Risk of adult-onset asthma increases with the number of allergic multimorbidities and decreases with age

\title{
Toppila-Salmi, Sanna
}

2019-12

Toppila-Salmi , S, Chanoine , S , Karjalainen , J , Pekkanen , J , Bousquet, J \& Siroux , V 2019 , ' Risk of adult-onset asthma increases with the number of allergic multimorbidities and decreases with age ' , Allergy : European journal of allergy and clinical immunology, vol. 74 , no. 12 , pp. 2406-2416 . https://doi.org/10.1111/all.13971

http://hdl.handle.net/10138/312949

https://doi.org/10.1111/all.13971

acceptedVersion

Downloaded from Helda, University of Helsinki institutional repository.

This is an electronic reprint of the original article.

This reprint may differ from the original in pagination and typographic detail.

Please cite the original version. 
DR. SANNA TOPPILA-SALMI (Orcid ID : 0000-0003-0890-6686)

DR. VALÉRIE SIROUX (Orcid ID : 0000-0001-7329-7237)

Article type : Original Article: Asthma and Lower Airway Disease

\section{Risk of adult-onset asthma increases with the number of allergic multimorbidities and decreases with age}

Sanna Toppila-Salmi ${ }^{1,2}$, Sebastien Chanoine ${ }^{3,4,5}$ Jussi Karjalainen $^{6}$, Juha Pekkanen ${ }^{7,8}$, Jean Bousquet ${ }^{9}$, Valérie Siroux ${ }^{3}$

Sanna Toppila-Salmi

${ }^{1}$ Haartman Institute, Medicum, PO Box 21 (Haartmaninkatu 3), 00014 University of Helsinki, Helsinki, Finland.

${ }^{2}$ Skin and Allergy Hospital, Helsinki University Hospital and University of Helsinki, PO Box 160 (Meilahdentie 2), 00029 Hospital District of Helsinki and Uusimaa, Helsinki, Finland. sanna.salmi@helsinki.fi

Sebastien Chanoine

${ }^{3}$ Institute for Advanced Biosciences, UGA / Inserm U 1209 / CNRS UMR 5309 joint research center Team of environmental epidemiology applied to reproduction and respiratory health, Site Santé Allée des Alpes, 38700 La Tronche

${ }^{4}$ Pôle Pharmacie, CHU Grenoble Alpes, 38000 Grenoble, France

${ }^{5}$ Université Grenoble Alpes, 38000 Grenoble, France

SChanoine@chu-grenoble.fr

Jussi Karjalainen

${ }^{6}$ Allergy Centre, Tampere University Hospital, PO BOX 2000 (Teiskontie 35), 33521 Tampere, Finland. Jussi.Karjalainen@pshp.fi

Juha Pekkanen

${ }^{7}$ Department of Public Health, PO Box 20 (Tukholmankatu 8 B), University of Helsinki, 00014 University of Helsinki, Helsinki, Finland

This article has been accepted for publication and undergone full peer review but has not been through the copyediting, typesetting, pagination and proofreading process, which may lead to differences between this version and the Version of Record. Please cite this article as doi: 10.1111/all.13971

This article is protected by copyright. All rights reserved. 
${ }^{8}$ Environmental Health, National Institute for Health and Welfare, PO Box 95, 70701 Kuopio, Finland. juha.pekkanen@helsinki.fi

Jean Bousquet

${ }^{9}$ Fondation FMC VIA-LR \& MACVIA-France, Montpellier, France, INSERM U 1168, VIMA : Ageing and chronic diseases Epidemiological and public health approaches, Villejuif, Université Versailles StQuentin-en-Yvelines, UMR-S 1168, Montigny le Bretonneux, France and Euforea, Brussels, Belgium jean.bousquet@orange.fr

Valérie Siroux

${ }^{3}$ Institute for Advanced Biosciences, UGA / Inserm U 1209 / CNRS UMR 5309 joint research center Team of environmental epidemiology applied to reproduction and respiratory health, Site Santé Allée des Alpes, 38700 La Tronche valerie.siroux@univ-grenoble-alpes.fr

\section{Address correspondence and reprint requests to:}

Sanna Toppila-Salmi, MD PhD, Skin and Allergy Hospital, Helsinki University Hospital, P.O. Box 160, 00029 HUS, Finland

Phone number: $+358-9-4711$

Telefax number: +358-9-19125155

E-mail address: sanna.salmi@helsinki.fi

Running title: Allergic multi-morbidity is associated with an increased risk of asthma

\section{Total}

Declarations:

\section{Ethics approval and consent to participate}

Approval for the study was obtained from the ethics committee at Tampere University Hospital (2/1996) and a written consent was obtained from all subjects.

\section{Competing interests}

STS has acted as paid consultant for Mylan Laboratories, ERT and Roche Products. SC reports personal fees from AstraZeneca, non-financial support from Boehringer Ingelheim, non-financial

This article is protected by copyright. All rights reserved. 
support from Actelion Pharmaceuticals, non-financial support from MSD, non-financial support from Astellas. JB reports personal fees and other from Chiesi, Cipla, Hikma, Menarini, Mundipharma, Mylan, Novartis, Sanofi-Aventis, Takeda, Teva, Uriach, other from Kyomed INNOV. All these are outside the submitted work. All other authors declare no conflicts of interest.

\section{Funding}

The study was supported in part by research grants from Finnish Medical Foundation, the Finnish Society of Allergology and Immunology, the Jane and Aatos Erkko Foundation, Paulo Foundation, State funding for university-level health research (TYH2018103), the Tampere Tuberculosis Foundation, the Väinö and Laina Kivi Foundation, and the Yrjö Jahnsson Foundation, as well as travel grants from the Researchers short mobility program (RSM) from the Joint funding from the Institut Français in Helsinki, the French Ministry of Education, Higher Education and Research and the Finnish Society for Science and Letters, and Tampere Medical association.

\section{Authors' contributions}

All authors participated on the planning and conception of the study and the analytical strategy, STS, SC and VS performed the data analyses and wrote the manuscript. All authors have assisted in data management, analyses and critical review of the manuscript.

\section{Acknowledgements}

We thank the following people for their valuable contributions: Professor Arpo Aromaa from the National Institute for Health and Welfare, MSc Heini Huhtala from the University of Tampere, Professor Timo Klaukka†, Riikka Lemmetyinen from University of Helsinki, and Professor Markku M. Nieminen from University of Tampere.

\section{Abstract}

Background: The aim was to study the association between allergic multimorbidity and adult-onset asthma considering the number of allergic diseases and the age effect.

Methods: We used population-based data from Finnish national registers including 1205 adults over 30 years of age with recently diagnosed asthma (age range: 30-93), matched for gender, age, and living region with one or two controls $(n=2050)$. Allergic rhinitis $(A R)$, allergic conjunctivitis $(A C)$ and allergic dermatitis $(A D)$, was defined from self-completed questionnaire. Conditional logistic

This article is protected by copyright. All rights reserved. 
regression adjusted on potential confounders (smoking, growing in countryside, childhood hospitalized infection/pneumonia, parental asthma/allergy, parental smoking, education level, professional training, number of siblings, and birth order) was applied to estimate the asthma risk associated with allergic multimorbidity.

Results: 1118 cases with asthma and 1772 matched controls were included [mean (sd, min-max) 53 (11, 31-71) years, $37 \%$ men)]. AR, AC or AD were reported by $50.2 \%, 39.6 \%, 33.8 \%$, respectively among subjects with asthma and $26.1 \%, 20.0 \%, 23.5 \%$, among controls. Compared to non-atopics, adult-onset asthma increased with the number of allergic diseases; adjusted OR for asthma [CI95\%] associated with 1, 2, and 3 allergic diseases were 1.95 [1.52-2.49], 2.87 [2.19-3.77], and 4.26 [3.075.90], respectively. The association between adult-onset asthma and $\geq 1$ allergic multimorbidity decreased with increasing age (3.52 [2.51-4.94], 2.44 [1.74-3.42] and 1.68 [1.04-2.71]) in subjects $<50$ years, 50-62 years and $>62$ years, respectively ( $p$ for age* $\geq 1$ allergic multimorbidity interaction, $.002)$.

Conclusions: Adult-onset asthma was positively associated with the number of allergic diseases and this association decreases with age.

\section{Key words}

asthma, atopic dermatitis, epidemiology, ocular allergy, rhinitis.

\section{Short title}

Allergic multimorbidity is associated with an increased risk of asthma in adults

Total word count:
Abbreviations
$A C=$ allergic conjunctivitis
$A D=$ allergic dermatitis
$A R=$ allergic rhinitis
$\mathrm{Cl}=$ confidence interval
FEV1 $=$ forced expiratory volume during the first second
$\mathrm{OR}=$ odds ratio
$\mathrm{PEF}=$ peak expiratory flow

This article is protected by copyright. All rights reserved. 
SII = Social Insurance Institution of Finland

\section{Background}

The prevalence of allergic diseases, including asthma, rhinitis, atopic dermatitis and food allergy, critically increased across the world over the past decades. Asthma, a common non-communicable disease, is a major public health issue, with over 300 million people affected worldwide $(1,2)$. In children, several cohort studies showed that allergic diseases were associated with increased risk of asthma $(3,4)$. A study of German children showed that asthma occurs in both sexes more frequently with coexisting allergies than as a single entity (4). In a secondary pediatric outpatient clinic, allergic conjunctivitis was a frequent co-morbidity to allergic rhinitis and to asthma and eczema (5).

Compared to pediatric population, less studies exist on the role of allergic diseases in asthma among adult population, and most of the studies only considered rhinitis. A study of a European adult population detected strong association between perennial rhinitis and asthma in nonatopic subjects (6). A nested case-control study from a cohort in a Tucson population showed that rhinitis was a significant risk factor for late-onset asthma in both atopic and nonatopic subjects (7). A Finnish population-based study found that allergic rhinoconjunctivitis doubles the risk for incident asthma (8). Further comprehensive studies simultaneously considering allergic rhinitis, allergic dermatitis and conjunctivitis are needed to have a better insight on the role of allergic multimorbidity on adultonset asthma.

Only few previous studies have addressed cohort- or age effect of the co-existing allergic diseases and asthma. It has been shown that the prevalence of allergic asthma has increased from 1996 to 2006 and further to 2016, while the prevalence of non-allergic asthma has remained stable (9). We have found that polysensitization was associated with asthma in adults $(10,11)$, and polysensitization and its asthma-risk increases in adults who were born after 1930 proposing a cohort and/or age affect between polysensitization and asthma in adults (12).

This article is protected by copyright. All rights reserved. 
Early detection and prevention of allergic multimorbidity that persists in adulthood could putatively reduce asthma burden in adults. As there is still limited knowledge of the putative causal effect between allergic multimorbidity and asthma in adults, the aim was to assess the association between allergic multimorbidity and adult-onset asthma in a large population-based case control study on asthma, the Adult Asthma in Finland (13). We hypothesized that each allergic disease, AR, $A D$ and $A C$, is positively associated with adult-onset asthma and that the asthma risk increases with the number of allergic multimorbidities. Our secondary hypothesis was that the asthma risk associated with allergic multimobidity increases with younger age.

\section{Methods}

\section{Study design}

This is a cross-sectional population-based case-control study of adult-onset asthma in Finland. We used a questionnaire of childhood and adulthood factors in 1996-97.

\section{Setting}

Population-based sample of asthmatics of Finland and their matched controls.

\section{Study Population}

The Adult Asthma in Finland is a population-based matched case control study conducted in 1997 (Figure 1) as previously described $(13,14)$. This study collected information from 1400 asthma patients older than 30 years of age with a recent asthma diagnosis ( $<1$ year). The asthmatics formed a random sample drawn from the Finnish Drug Reimbursement register, maintained by Social Insurance Institution (SII) of Finland, in which all newly diagnosed cases in the study population could be identified by the asthma drug reimbursement decision of diagnosed asthma. In detail, the reimbursement right is granted by certificate that has been made by patient's physician. This certificate has to include background information, clinical exam's results, lung function test results as well as findings and conclusions after asthma treatment test period of 6 months. These certificates are reviewed case by case by SII's physician, who gives the reimbursement right. SII stores the certificates, in which the lung functions test results are referred. Lung function test parameters are not stored by SII as variable data, yet this data are stored by the patient's hospital. All asthmatics fulfilled the following criteria for doctor-diagnosed asthma in this register: typical history, clinical features, and asthma course, at least one of the following physiologic criteria: (i) a variation of $20 \%$ or greater in diurnal peak expiratory flow (PEF) recording (reference to maximal

This article is protected by copyright. All rights reserved. 
value); (ii) an increase of $15 \%$ or greater in PEF or forced expiratory volume in 1 second (FEV1) with b-agonist; or (iii) an decrease of $15 \%$ or greater in PEF or FEV1 in exercise testing. This method of case ascertainment has been validated earlier $(15,16)$. The asthmatics were matched for gender, age ( \pm 2 years), and living region (area of residence by postal code) with two controls drawn from National Registers, through Mini Finland Health Survey, and through a population register (Figure 1) (13). Questionnaire consisted of demographic questions (for both groups), and asthma-specific questions for asthma patients. The proportion of the responders in asthma and control group was $86.1 \%$ and $73.2 \%$, correspondingly. Approval for the study was obtained from the ethical committee at Tampere University Hospital and a written consent was obtained from all subjects. Selected controls did not have in 1997 a valid decision for drug reimbursement of diagnosed asthma in the Drug Reimbursement register. To make sure that the controls did not have accidentally an asthma, and that cases had asthma, all subjects were asked doctor-diagnosed asthma and current asthma medication, and asthmatics were additionally asked age at onset of asthma symptoms, the place of physician-diagnosed asthma and severity of asthma symptoms. We found that only $1.4 \%$ of the controls responded that they have a doctor diagnosed asthma with current asthma medication, and $0.9 \%$ of the asthmatics responded that they do not have (Table 1 ).

\section{Outcomes}

\section{Definition of adult-onset asthma and severe asthma}

All asthmatics fulfilled the following criteria for asthma: typical history, clinical features, and asthma course; at least one of the following physiologic criteria: (i) a variation of $20 \%$ or greater in diurnal peak expiratory flow (PEF) recording (reference to maximal value); (ii) an increase of $15 \%$ or greater in PEF or forced expiratory volume in 1 sec (FEV1) with $\beta$-agonist; or (iii) an decrease of $15 \%$ or greater in PEF or FEV1 in exercise testing. This method of case ascertainment has been validated earlier $(15,16)$. The responders were asked the year of doctor-diagnosed asthma. The (mean \pm SD) age of doctor-diagnosed asthma was $48.8 \pm 12.7$ years. All responders were asked whether they have had cough/dyspnea with wheeze ever (Table 1). The asthmatics were asked age at asthma onset, severity of asthma symptoms, and the place of physician-diagnosed asthma (Table 1).

Severe asthma was defined as self-reported severe asthma symptoms AND regular impairment caused by asthma AND ( $\geq 1$ oral corticosteroid course/regular oral corticosteroids due to asthma during the past 12 months AND/OR wake up in the night due to asthma $\geq 1 /$ week).

This article is protected by copyright. All rights reserved. 


\section{Definition of allergic multimorbidity}

AR was asked by the question 'Have you ever had hay fever or other rhinitis symptoms that are related to pollens or animals?' (No, Yes, Don't know). AC and AD were asked "Do you get any other allergic symptoms? Skin symptoms, Eye symptoms, Airway symptoms, Other, what?" Both missing responses (representing between $4.4 \%$ and $7.7 \%$ among asthmatics, and between $3.6 \%$ and 9.3\% among controls), and "I don't know" responses (representing between 6.0 \% and $12.5 \%$ among asthmatics, and between $5.0 \%$ and $7.7 \%$ among controls) to $A R, A D$ and $A C$ questions were regarded as "No" in the main analysis. In the complete case analysis, the "I don't know" values and missing values were both regarded as missing values.

\section{Statistical analyses}

The comparisons of demographic data or allergic multimorbidity prevalence between asthma and control groups were performed by conditional logistic regression and were reported as odds ratios (OR) with $95 \%$ confidence intervals.

The association between allergic multi-morbidity and adult-onset asthma was conducted considering 3 consecutive allergic multimorbidity variables: (i.) $\geq 1$ allergic disease (main model); (ii.) the number of allergic multi-morbidities to address a possible dose-response relationship; (iii.) type of allergic disease to test whether each allergic multimorbidity confers an asthma risk of similar magnitude. All models were adjusted by age, gender and living region. The models (i.-iii.) were also performed with adjustment on the following potential confounding factors identified in the directed-acyclic-graph (figure S1) : gender, age (continuous), living region, smoking (never vs. ever), growing in countryside, severe childhood infections (pneumonia before or during school age and/or hospitalization due to infection at $\leq 3$ years of age), parental asthma/allergy, parental smoking, education level (baccalaureate; secondary; primary school), professional training (completed professional college/university; courses/completed trade school; no), number of siblings, and birth order (13,1720). In further analyses, 2 variables were successively tested as potential effect modifier in the association between $\geq 1$ allergic multimorbidity and adult-onset asthma by adding an interaction term in the regression models: 1 ) age, considering three age categories equal in size: subjects $<50$ years, 50-62 years and $>62$ years, following previous findings indicating that risk of adult-onset asthma associated with polysensitization decreases with age (12); 2) Sex, to address a sex effect in the association between allergic multimorbidity and adult-onset asthma, as previously suggested (21). In addition, the association between $\geq 1$ allergic multimorbidity and asthma was stratified by the asthma severity status (mild-moderate vs. severe), to address the hypothesis that allergic multimorbidity could be associated with more severe asthma, as suggested in children (22).

This article is protected by copyright. All rights reserved. 
Finally, sensitivity analyses were conducted to address the robustness of the results 1) to missingness, by including only subjects without missing data for each allergic multimorbidity question (missing values were a priori imputed as "No" for each allergy multimorbidity question); 2) to the case and control definition, by excluding 99 subjects with potential misclassification given the questionnaire data (24 controls who reported using current regular asthma medication, 10 cases who did not report using and 65 cases who reported onset asthma before 15 years of age).

P-values less than 0.05 were considered statistically significant. Statistics were performed with SPSS Base 24 Statistical Software Package (SPSS, Chicago, IL, USA).

\section{Results}

\section{Subject characteristics}

The total number of asthma cases with available data was 1118 and matched controls was 1772 (Table 1). The mean \pm SD, min-max age of the subjects was $53 \pm 11,31-71$ years. The proportion of females was $63 \%$. The proportion of asthma cases having self-reported AR, AC or AD were $50.2 \%$, $39.6 \%, 33.8 \%$, respectively in comparison to control group $26.1 \%, 20.0 \%, 23.5 \%$, respectively (Table 1, Table 4). As compared to controls, asthma cases were more often ever smoker, had more often severe childhood infections and parental asthma/allergy, parental smoking, and had a lower education level and professional training (Table 1). Among asthma cases, 10\% had severe asthma.

\section{At least one allergic multimorbidity and adult-onset asthma}

The presence of at least one allergic disease was associated with an increased risk for adult onset asthma, with an adjusted OR [CI95\%] of (2.60 [2.11-3.19], Table 2). This association between adultonset asthma and $\geq 1$ allergic multimorbidity was slightly higher in females than in males (2.80 [2.14$3.66]$ and 2.40 [1.70-3.39], respectively), but there was no statistically significant gender difference (adjusted $p$ value for interaction was 0.45 , Figure 2, Table 2). Age was an effect modifier in this association (adjusted $\mathrm{p}$ value for interaction was 0.002 ). The odds ratio of adult-onset asthma associated with $\geq 1$ allergic multimorbidity increased with decreasing age: adjusted OR [CI95\%] were 3.52 [2.51-4.94], 2.44 [1.74-3.42] and 1.68 [1.04-2.71] in subjects $<50$ years, 50-62 years and $>62$ years, respectively (Table 2). The association was stronger in those with severe asthma, as compared to those with mild-moderate asthma, although the interaction term was nonsignificant (adjusted OR [Cl95\%] were 4.90 [1.95-12.32] and 2.56 [2.06-3.19], respectively) (Table 2). The sensitivity analysis

This article is protected by copyright. All rights reserved. 
conducted on complete case analysis $(n=1955)$ showed similar patterns of association and lead to higher adjusted OR point estimates (e.g. risk associated for $\geq 1$ allergic disease was 3.31 [2.56-4.28], 3.73 [2.67-5.22], 3.07 [1.97-4.78] in all, females and males respectively, and 4.58 [3.00-6.97], 3.80 [2.41-6.00], 1.72 [0.95-3.14], in subjects $<50$ years, 50-62 years and $>62$ years, respectively.

\section{Number of allergic diseases and adult-onset asthma}

When considering the number of allergic diseases, a dose-response relationship was observed: adjusted OR [Cl95\%] for 1, 2, and 3 allergic diseases were 1.95 [1.52-2.49], 2.87 [2.19-3.77], and 4.26 [3.07-5.90] as compared to no allergic disease, respectively (Figure 2, Table 3, p for trend test $<0.0001)$. A similar pattern of association was observed in females, with OR [CI95\%] 2.08 [1.51-2.86], 3.06 [2.18-4.30], and 4.08 [2.80-5.94], respectively and in males OR [CI95\%] were 1.78 [1.18-2.68], 2.82 [1.72-4.63], and 6.51 [2.92-14.46], respectively ( $p$ value for trend test $<0.001$ in males and in females). In the complete case analysis adjusted OR [CI95\%] were 2.27 [1.66-3.10], 3.67 [2.66-5.07], 5.15 [3.56-7.45], respectively. Sensitivity analysis on the definition of asthma and control showed very similar results (Figure S2).

\section{Type of allergic multimorbidities and adult-onset asthma}

In adjusted models, all single and combined allergic diseases were significantly associated with higher risk of asthma with OR $>2.2$ except AD only, for which the adjusted OR [CI95\%] estimated was 1.25 [0.87-1.80] (Table 3). The association between adult-onset asthma and AC only or AR only was of similar magnitude (2.35 [1.48-3.71] and 2.53 [1.83-3.50], respectively, Table 3). The presence of all three allergic diseases ( $A R+A C+A D$ ) had the strongest effect on adult-onset asthma (adjusted OR [CI95\%] 4.19 [3.02-5.81]) (Table 3). The next strongest association with adult-onset asthma was observed for co-existing AR+AC, 3.04 [2.17-4.26] (Table 3). The sensitivity analysis on complete case analysis ( $n=1955)$ showed similar patterns of association, and tended to increase OR point estimates (Table S1).

\section{Discussion}

In this population-based case-control study we detected strong associations between allergic diseases and asthma diagnosis in adulthood. Our major finding was that adult-onset asthma was positively associated with the number of allergic diseases and this association decreases with age.

This article is protected by copyright. All rights reserved. 
The strong association between allergic multimorbidity and adult-onset asthma observed in this study extends to adulthood observations well demonstrated in children. The association between asthma and allergic multimorbidity, including rhinitis, conjunctivitis, and dermatitis, is well described in children (3). Causal network analysis in school-aged children has shown that allergen sensitization, allergic inflammation, environmental tobacco smoke exposure, pulmonary physiology, and rhinitis severity explained over half of the variance in asthma severity (22). However, there has been limited knowledge of the effect of allergic multimorbidity on asthma-risk in adults. In a previous study we found that polysensitization was associated with asthma in adults (10). In agreement with these findings, here we demonstrate that allergic multimorbidity is associated with asthma diagnosed in adulthood. Noteworthy, we showed a dose-response relationship between the number of allergic multimorbidities and asthma. Therefore, our results suggest that the multimorbid approach of allergic diseases should consider multiple organs (nose, eye, skin and lower airways). These results are in accordance with previous data in adults demonstrating that the asthma-plus-rhinitis multimorbidity is associated with strong polysensitization and combined the sensitization pattern of both the AR only and asthma only phenotypes (23). These observations were recently extending by considering conjunctivitis in addition to rhinitis and asthma; the study showed that increase in allergic multimorbidity, irrespective of the disease (rhinitis, conjunctivitis and asthma) was associated with a significant increase in the number of IgE-reactivities to respiratory allergens (24). In addition, we have previously detected in a smaller adult population that allergic rhinitis and/or allergic conjunctivitis (AR/AC) and polysensitization co-associate with adult asthma (11).

We found that the association between adult-onset asthma and allergic multimorbidity decreased with age. These findings of a stronger increase in asthma risk associated with allergic multimorbidity in the youngest group are in line with results from a Swedish study showing that the prevalence of allergic asthma has increased during the past two decades, while the prevalence of non-allergic asthma has remained on a stable prevalence level (9). In addition, our findings are in agreement with our previous observation showing that polysensitization was associated with asthma in adults (10), and this association was stronger in adults who were born after 1930 (12). Altogether, these observations suggest that the proportion of allergic multimorbidity and allergic polysensitization among asthmatics is increasing with later decades of birth. To which extent this observation results from a cohort-effect, e.g. change in host-microbiome-environmental interactions during development over time, and from an ageing effect remains unknown and requires further studies (25).

This article is protected by copyright. All rights reserved. 
Childhood asthma is characterized by a predominance of allergic multimorbidity in males (26). Pediatric studies have also shown that allergic multimorbidity and/or polysensitization associates with asthma persistence (27). A follow-up study including French children showed that risk factors for asthma persisting into of 13 years of age were allergic sensitization to multiple airborne allergens, initial atopic dermatitis, severe recurrent wheezing and hypereosinophilia (28). A previous European population-based study has focused on atopic vs. non-atopic asthma instead of multimorbidity, and showed that female gender is an independent risk for non-atopic asthma (21). This observation was not explained by differences in smoking, obesity and diagnoses between males and females (21). Our study did not bring evidence of strong gender differences in the association between allergic multimorbidity and asthma in adulthood.

Although the co-occurrence of allergic diseases and asthma is more common than expected by chance, particularly in children, the extent to which the allergic diseases and asthma share a common cause is still not fully understood. A large European GWAs on asthma and IgE showed no overlap between loci strongly associated with asthma and those strongly associated with IgE levels, except in HLA-DR (29), suggesting that the causal role of IgE in the development of asthma might be lower than expected. In addition, a study focusing on eczema, asthma and rhinitis multimorbidity showed that although IgE sensitization is associated with excess allergic multimorbidity (including asthma), its presence accounted for less than $40 \%$ of multimobidity, suggesting that IgE sensitization can no longer be considered as the dominant causal mechanism of allergic multimorbidity (30). Our study addressed the association between allergic multimorbidity and adult-onset asthma, which has less been studied. Yet it remains open, to which extent the association between allergic multimorbidity and asthma is a true causal association and to which it extent it relies on shared mechanisms between asthma and allergic diseases.

Our data, including $10 \%$ of adults with severe asthma, suggest that allergic multimorbidity might be more strongly associated with severe asthma than milder form of asthma, although asthma severity was not identified as a significant modifier effect given the large confidence intervals. Our results are in line with results from previous publications (31). Among adult women with asthma, a clustering approach using drug based administrative databases identified three multimorbidity patterns associated with asthma, including a pattern mainly characterized by "allergic multimorbidity" that represented $33 \%$ of the population (31). This multimobidity profile showed an increased risk of subsequent uncontrolled asthma and asthma exacerbations as compared to a profile characterized

This article is protected by copyright. All rights reserved. 
by "few multimorbidity" and, importantly, this risk was of similar magnitude than the risk observed for the "metabolic multimorbidity" profile (31). Thus, allergic diseases affect morbidity life-long (32), although, in terms of mortality previous studies indicate that AR/AC did not explain excess mortality among asthmatic adults (13). Overall, it is likely that asthma with allergic multimorbidity represent phenotypes that considerably differ from asthma alone in terms of mechanisms, severity and prognosis. More studies to prove this are needed.

\section{Strengths and limitations}

The strengths of the study include the large population-based design that mitigates potential for sampling bias, high age range and a historical aspect of subjects born in early 1900's, and a high responder rate. In addition, given the detailed information recorded in the study, we were able to adjust for a large set of potential confounders in the analysis. Nevertheless, the association reported could be partly biased by residual for confounding, either due to missing potential confounders in the regression model (i.e. occupational exposure), or due to limited accuracy in the assessment of some independent variables (i.e. the smoking variable does not take into account for the amount and the duration of smoking), caution is needed about extrapolating our results to another population; the results of this study should be confirmed in other population and countries. The weaknesses of our study include the limited statistical power of some analysis on sub-groups, in particular the analysis addressing the modifying effect of asthma severity. Despite the efforts in the definition of cases and controls in this study, we acknowledge that few controls reported doctordiagnosed asthma with current asthma medication (although not fulfilling asthma diagnosis of the reimbursement register), and that a small portion of asthmatics might had childhood-onset asthma that relapsed in adulthood. However, sensitivity analyses relying on more stringent definitions of cases and controls using questionnaire data led to the same conclusions, indicating that our findings are not biased by potential misclassifications. In addition, a memory bias in the report of allergic diseases might have occurred, and more likely in the oldest age group, which would lead to bias towards the null the association in particular in the oldest age group; therefore, if such a memory biased occurred, it might have partly contributing in showing strongest associations in the youngest age group. Nevertheless, we believe that, if this bias occurred, it was of limited impact on our main results because subjects had the possibility to reply "I don't know" and the complete case analysis that considered "I don't know" as missing values showed similar patterns of associations with stronger magnitude of the effects and the age modifying effect remained significant. The crosssectional design does not allow assertion on the causal direction of associations, however because

This article is protected by copyright. All rights reserved. 
asthma was recently diagnosed (past year) given to the study design, we might hypotheses that allergic multimorbities occurred before asthma on most of the cases.

\section{Conclusion}

The presence of allergic multimorbid diseases was associated with asthma diagnosed in individuals over 30 years of age. This association was gradually increasing with the number of allergic diseases and was stronger in the younger age group. Altogether our results support that allergic multimorbidity becomes an important concept across the life cycle. Further research on prospective cohorts would be needed to confirm these results.

\section{References}

(1) Bousquet J, Hellings PW, Agache I, Bedbrook A, Bachert C, Bergmann KC, et al. ARIA 2016: Care pathways implementing emerging technologies for predictive medicine in rhinitis and asthma across the life cycle. Clin Transl Allergy 2016 Dec 30;6:47-016-0137-4. eCollection 2016.

(2) Reddel HK, Bateman ED, Becker A, Boulet LP, Cruz AA, Drazen JM, et al. A summary of the new GINA strategy: a roadmap to asthma control. Eur Respir J 2015 Sep;46(3):622-639.

(3) Anto JM, Bousquet J, Akdis M, Auffray C, Keil T, Momas I, et al. Mechanisms of the Development of Allergy (MeDALL): Introducing novel concepts in allergy phenotypes. J Allergy Clin Immunol 2017 Feb;139(2):388-399.

(4) Gough H, Grabenhenrich L, Reich A, Eckers N, Nitsche O, Schramm D, et al. Allergic multimorbidity of asthma, rhinitis and eczema over 20 years in the German birth cohort MAS. Pediatr Allergy Immunol 2015 Aug;26(5):431-437.

(5) Gradman J, Wolthers OD. Allergic conjunctivitis in children with asthma, rhinitis and eczema in a secondary outpatient clinic. Pediatr Allergy Immunol 2006 Nov;17(7):524-526.

(6) Leynaert B, Bousquet J, Neukirch C, Liard R, Neukirch F. Perennial rhinitis: An independent risk factor for asthma in nonatopic subjects: results from the European Community Respiratory Health Survey. J Allergy Clin Immunol 1999 Aug;104(2 Pt 1):301-304.

(7) Guerra S, Sherrill DL, Martinez FD, Barbee RA. Rhinitis as an independent risk factor for adultonset asthma. J Allergy Clin Immunol 2002 Mar;109(3):419-425.

(8) Pallasaho P, Juusela M, Lindqvist A, Sovijarvi A, Lundback B, Ronmark E. Allergic rhinoconjunctivitis doubles the risk for incident asthma--results from a population study in Helsinki, Finland. Respir Med 2011 Oct;105(10):1449-1456.

(9) Backman H, Raisanen P, Hedman L, Stridsman C, Andersson M, Lindberg A, et al. Increased prevalence of allergic asthma from 1996 to 2006 and further to 2016-results from three population surveys. Clin Exp Allergy 2017 Nov;47(11):1426-1435.

This article is protected by copyright. All rights reserved. 
(10) Toppila-Salmi S, Huhtala H, Karjalainen J, Renkonen R, Makela MJ, Wang DY, et al. Sensitization pattern affects the asthma risk in Finnish adult population. Allergy 2015 Sep;70(9):1112-1120.

(11) Adjers K, Luukkainen A, Pekkanen J, Hurme M, Huhtala H, Renkonen R, et al. Self-Reported Allergic Rhinitis and/or Allergic Conjunctivitis Associate with IL13 rs20541 Polymorphism in Finnish Adult Asthma Patients. Int Arch Allergy Immunol 2017;172(2):123-128.

(12) Toppila-Salmi S, Luukkainen A, Lemmetyinen R, Karjalainen J, Huhtala H, Renkonen R, et al. Birth decade affects the sensitization pattern and asthma risk in Finnish adult population. Allergy 2017 Nov;72(11):1791-1795.

(13) Lemmetyinen RE, Karjalainen JV, But A, Renkonen RLO, Pekkanen JR, Toppila-Salmi SK, et al. Higher mortality of adults with asthma: A 15-year follow-up of a population-based cohort. Allergy 2018 Jul;73(7):1479-1488.

(14) Pasternack R, Huhtala H, Karjalainen J. Chlamydophila (Chlamydia) pneumoniae serology and asthma in adults: a longitudinal analysis. J Allergy Clin Immunol 2005 Nov;116(5):1123-1128.

(15) Karjalainen A, Kurppa K, Martikainen R, Klaukka T, Karjalainen J. Work is related to a substantial portion of adult-onset asthma incidence in the Finnish population. Am J Respir Crit Care Med 2001 Aug 15;164(4):565-568.

(16) Kauppi P, Laitinen LA, Laitinen H, Kere J, Laitinen T. Verification of self-reported asthma and allergy in subjects and their family members volunteering for gene mapping studies. Respir Med 1998 Nov;92(11):1281-1288.

(17) Piipari R, Jaakkola JJ, Jaakkola N, Jaakkola MS. Smoking and asthma in adults. Eur Respir J 2004 Nov;24(5):734-739.

(18) Lampi J, Koskela H, Hartikainen AL, Ramasamy A, Couto Alves A, Jarvelin MR, et al. Farm environment during infancy and lung function at the age of 31: a prospective birth cohort study in Finland. BMJ Open 2015 Jul 22;5(7):e007350-2014-007350.

(19) Burgess JA, Abramson MJ, Gurrin LC, Byrnes GB, Matheson MC, May CL, et al. Childhood infections and the risk of asthma: a longitudinal study over 37 years. Chest 2012 Sep;142(3):647-654.

(20) Ekerljung L, Sundblad BM, Ronmark E, Larsson K, Lundback B. Incidence and prevalence of adult asthma is associated with low socio-economic status. Clin Respir J 2010 Jul;4(3):147-156.

(21) Leynaert B, Sunyer J, Garcia-Esteban R, Svanes C, Jarvis D, Cerveri I, et al. Gender differences in prevalence, diagnosis and incidence of allergic and non-allergic asthma: a population-based cohort. Thorax 2012 Jul;67(7):625-631.

(22) Liu AH, Babineau DC, Krouse RZ, Zoratti EM, Pongracic JA, O'Connor GT, et al. Pathways through which asthma risk factors contribute to asthma severity in inner-city children. J Allergy Clin Immunol 2016 Oct;138(4):1042-1050.

(23) Siroux V, Ballardini N, Soler M, Lupinek C, Boudier A, Pin I, et al. The asthma-rhinitis multimorbidity is associated with IgE polysensitization in adolescents and adults. Allergy 2018 Jul;73(7):1447-1458.

This article is protected by copyright. All rights reserved. 
(24) Siroux V, Boudier A, Nadif R, Lupinek C, Valenta R, Bousquet J. Association between asthma, rhinitis and conjunctivitis multimorbidities with molecular IgE sensitization in adults. Allergy 2018 Nov 25.

(25) Lynch SV, Boushey HA. The microbiome and development of allergic disease. Curr Opin Allergy Clin Immunol 2016 Apr;16(2):165-171.

(26) Gabet S, Just J, Couderc R, Bousquet J, Seta N, Momas I. Early polysensitization is associated with allergic multimorbidity in PARIS birth cohort infants. Pediatr Allergy Immunol 2016 Dec;27(8):831-837.

(27) Moustaki M, Loukou I, Tsabouri S, Douros K. The Role of Sensitization to Allergen in Asthma Prediction and Prevention. Front Pediatr 2017 Jul 31;5:166.

(28) Amat F, Vial A, Pereira B, Petit I, Labbe A, Just J. Predicting the long-term course of asthma in wheezing infants is still a challenge. ISRN Allergy 2011 Jul 27;2011:493624.

(29) Moffatt MF, Gut IG, Demenais F, Strachan DP, Bouzigon E, Heath S, et al. A large-scale, consortium-based genomewide association study of asthma. N Engl J Med 2010 Sep 23;363(13):1211-1221.

(30) Pinart M, Benet M, Annesi-Maesano I, von Berg A, Berdel D, Carlsen KC, et al. Comorbidity of eczema, rhinitis, and asthma in IgE-sensitised and non-IgE-sensitised children in MeDALL: a population-based cohort study. Lancet Respir Med 2014 Feb;2(2):131-140.

(31) Chanoine S, Sanchez M, Pin I, Temam S, Le Moual N, Fournier A, et al. Multimorbidity medications and poor asthma prognosis. Eur Respir J 2018 Apr 12;51(4):10.1183/13993003.021142017. Print 2018 Apr.

(32) Savage JH, Matsui EC, McCormack M, Litonjua AA, Wood RA, Keet CA. The association between asthma and allergic disease and mortality: a 30-year follow-up study. J Allergy Clin Immunol 2014 May;133(5):1484-7, 1487.e1-5.

\section{Figure 1.}

\section{Flow chart of the study population.}

Asthmatics drawn from the the Finnish Drug Reimbursement register were over 30 years old, recently (in 2 years) diagnosed asthmatics, that had received the right for asthma medication reimbursement. Two controls were drawn from National registers and were matched for gender, age, and living region.

\section{Figure 2.}

\section{Forest plot summarizing the associations between allergic disease(s) and adult-onset asthma.}

Adjusted $\mathrm{OR}$ and $95 \% \mathrm{Cl}$ of adult-onset asthma are presented for $\geq 1$ allergic disease (in all, by gender and by age group) and for the number of allergic diseases. Models were adjusted on gender, age and region, smoking, growing in countryside, childhood pneumonia/hospitalization due to infection,

This article is protected by copyright. All rights reserved. 
parental asthma/allergy, parental smoking, education level, professional training, number of siblings, and birth order. The total number of asthmatics is 930 and matched controls is 1289 .

This article is protected by copyright. All rights reserved. 
Table 1. Association between self-reported demographic factors and asthma diagnosis.

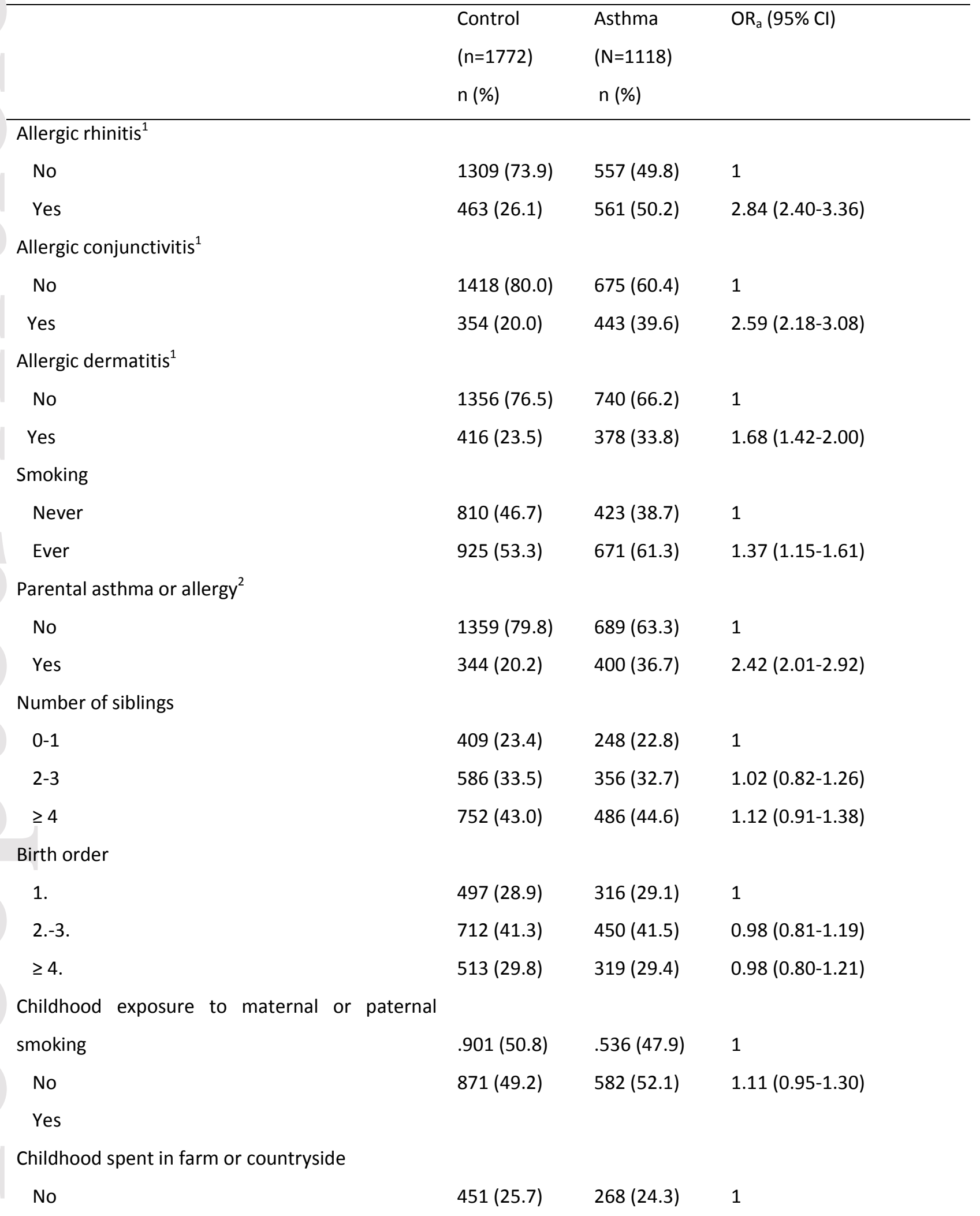

This article is protected by copyright. All rights reserved. 
Yes

Severe childhood infections ${ }^{3}$

No

Yes

Education level

Baccalaureate

Secondary school / equivalent

Primary school or less

Training

Professional college /University

Courses / Trade school

No

Severe asthma ${ }^{4}$

Age at onset of asthma symptoms, $n(\%)^{5,6}$

In childhood

At school age

Over $15 \mathrm{y}$ of age

In adulthood

The place of physician-diagnosed asthma, $\mathrm{n}(\%)^{5,7}$

Primary care

Hospital

Asthma symptoms, $\mathrm{n}(\%)^{5,7}$

None to mild

Moderate

Severe

Doctor-diagnosed asthma with current asthma medication $^{8}$

No

Yes
$1305(74.3) \quad 833(75.7) \quad 1.13(0.94-1.37$

$\begin{array}{lll}1515(87.6) & 881(81.6) & 1 \\ 214(12.4) & 198(18.4) & 1.16(1.31-2.04)\end{array}$

$344(19.8) \quad 156(14.3) \quad 1$

$429(24.7) \quad 272(25.0) \quad 1.42(1.10-1.83)$

$961(55.4) \quad 661(60.7) \quad 1.76(1.37-2.25)$

$485(29.0) \quad 239(23.4) \quad 1$

$798(47.7) \quad 521(51.1) \quad 1.35(1.11-1.65)$

$389(23.3) \quad 260(25.5) \quad 1.51(1.17-1.93)$

$110(10.0)$

$37(3.4)$

$28(2.6)$

$23(2.1)$

$992(91.9)$

$283(25.6)$

$822(74.4)$

$26023.3)$

$725(64.8)$

$120(10.7)$

$1669(98.6) \quad 10(0.9) \quad 1$

$24(1.4) \quad 1056(99.1) \quad 107.5(63.8-181.2)$

${ }^{1}$ self-reported allergic disease ever, ${ }^{2}$ missing value $=$ The subject responded that he/she does not have either of the asked relatives (mother or father). ${ }^{3}$ Severe childhood infections = Pneumonia before or during school age and/or hospitalization due to infection at $\leq 3 \mathrm{yrs}$ of age. ${ }^{4}$ Self-reported severe asthma symptoms AND regular harm caused by asthma AND ( $\geq 1$ peroral corticosteroid

This article is protected by copyright. All rights reserved. 
course/regular corticosteroids due to asthma during the past 12 months AND/OR wake up in the night due to asthma at $\geq 1$ /week). ${ }^{5}$ The questions were asked only from the asthmatics. ${ }^{6}$ The number of missing responses from asthmatics was 38. ${ }^{7}$ The number of missing responses from asthmatics was $13 .{ }^{8}$ The number of missing responses from asthmatics was 52 and from nonasthmatics $79 . \mathrm{OR}_{\mathrm{a}}=$ odds ratio adjusted for gender, age and region.

This article is protected by copyright. All rights reserved. 
Table 2. Association of $\geq 1$ allergic disease with adult onset asthma, in the whole population and stratified by gender, age group and asthma severity. The reference group for OR-values are the controls.

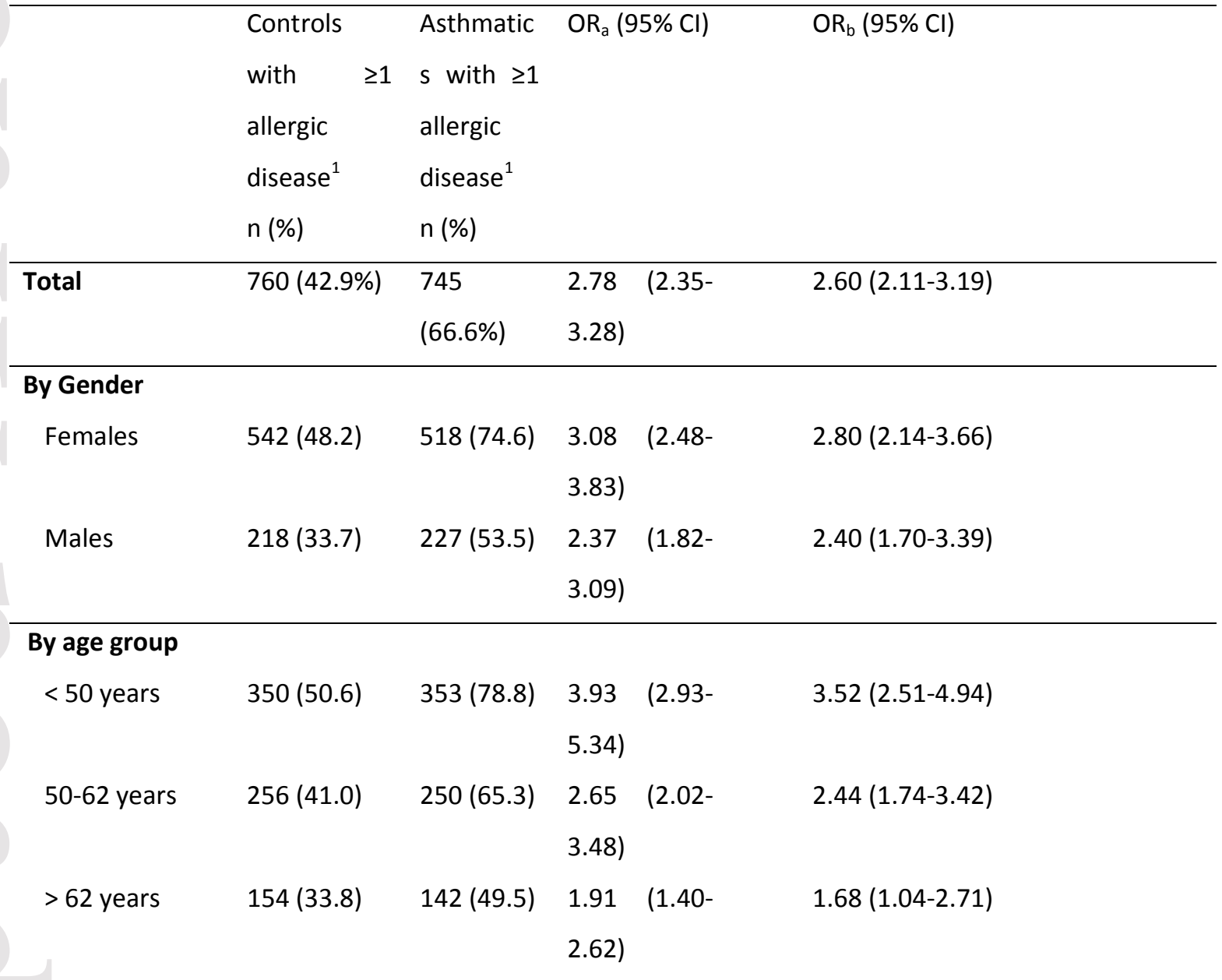

\section{By asthma}

severity status

$\begin{array}{llllll}\text { Mild-moderate } & 485(30.3) & 675(67.0) & 2.73 & (2.29- & 2.56(2.06-3.19) \\ & & & 3.26) & \\ \text { Severe } & 57(33.7) & 70(63.6) & 3.18 & (1.88- & 4.90(1.95-12.32) \\ & & & 5.40)\end{array}$

The total number of asthmatics is 1118 and matched controls is 1772 .

Allergic disease ${ }^{1}=$ presence of at least one of the following self-reported diseases ever: allergic rhinitis, allergic conjunctivitis, allergic dermatitis. $\mathrm{OR}_{\mathrm{a}}=$ odds ratio adjusted for gender, age and region; $\mathrm{OR}_{\mathrm{b}}=$ adjusted for gender, age and region, as well as for selected covariates: smoking,

This article is protected by copyright. All rights reserved. 
growing in countryside, childhood pneumonia/hospitalization due to infection, parental asthma/allergy, parental smoking, education level, professional training, number of siblings, and birth order.

p for interaction:

$\geq 1$ allergic disease* gender $p=.13$, adjusted $p=.45$

$\geq 1$ allergic disease* asthma severity status $p=.59$, adjusted $p=.72$

$p$ for trend: $\geq 1$ allergic disease* age $p=.016$, adjusted $p=.002$

This article is protected by copyright. All rights reserved. 
Table 3. Association of different combinations of allergic diseases with adult-onset asthma.

\begin{tabular}{|c|c|c|c|c|}
\hline & $\begin{array}{l}\text { Controls } \\
(\mathrm{n}=1772) \\
\mathrm{n}(\%)\end{array}$ & $\begin{array}{l}\text { Asthmatics } \\
(\mathrm{n}=1118) \\
\mathrm{n}(\%)\end{array}$ & $\mathrm{OR}_{\mathrm{a}}(95 \% \mathrm{Cl})$ & $\mathrm{OR}_{\mathrm{b}}(95 \% \mathrm{Cl})$ \\
\hline $\begin{array}{l}\text { Model 1: Nu } \\
\text { diseases }^{1}\end{array}$ & ber of allergi & & & \\
\hline 0 & $1012(57.1)$ & $373(33.4)$ & 1 & 1 \\
\hline 1 & $402(22.7)$ & $297(26.6)$ & $\begin{array}{l}2.09 \\
2.57)\end{array}$ & $1.95(1.52-2.49)$ \\
\hline 2 & $243(13.7)$ & $259(23.2)$ & $\begin{array}{l}3.09 \quad(2.46- \\
3.87)\end{array}$ & $2.87(2.19-3.77)$ \\
\hline 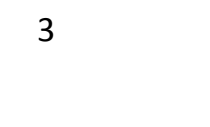 & $115(6.5)$ & $189(16.9)$ & $\begin{array}{l}4.36 \quad(3.32- \\
5.72)^{2}\end{array}$ & $4.26(3.07-5.90)^{2}$ \\
\hline $\begin{array}{l}\text { Model 2: } T \\
\text { diseases }^{1}\end{array}$ & pe of allergi & & & \\
\hline No & $1012(57.1)$ & $373(33.4)$ & 1 & 1 \\
\hline Only AR & $150(8.5)$ & $152(13.6)$ & $\begin{array}{l}2.78 \quad(2.12- \\
3.65)\end{array}$ & $2.53(1.83-3.50)$ \\
\hline Only AC & $60(3.4)$ & $68(6.1)$ & $\begin{array}{l}3.13 \quad(2.14- \\
4.58)\end{array}$ & $2.35(1.48-3.71)$ \\
\hline Only AD & $192(10.8)$ & 77 (6.9) & $\begin{array}{l}1.18 \quad(0.87- \\
1.59)\end{array}$ & $1.25(0.87-1.80)$ \\
\hline$A R+A C$ & $134(7.6)$ & $147(13.1)$ & $\begin{array}{l}3.00 \quad(2.26- \\
3.98)\end{array}$ & $3.04(2.17-4.26)$ \\
\hline$A R+A D$ & $64(3.6)$ & $73(6.5)$ & $\begin{array}{l}3.39 \quad(2.32- \\
4.94)\end{array}$ & $2.81(1.81-4.35)$ \\
\hline$A C+A D$ & $45(2.5)$ & $39(3.5)$ & $\begin{array}{l}2.50 \\
4.02)\end{array}$ & $2.20(1.28-3.78)$ \\
\hline$A R+A C+A D$ & $115(6.5)$ & 189 (16.9) & $\begin{array}{l}4.33 \quad(3.30- \\
5.70)^{2}\end{array}$ & $4.19(3.02-5.81)^{2}$ \\
\hline
\end{tabular}

This article is protected by copyright. All rights reserved. 
pneumonia/hospitalization due to infection, parental asthma/allergy, parental smoking, education level, professional training, number of siblings, and birth order.

${ }^{2}$ small differences in the estimates between model 1 and 2 comes from differences of estimating methods.

This article is protected by copyright. All rights reserved. 
Table 4. Association of each allergic disease with adult onset asthma in all subjects by conditional logistic regression.

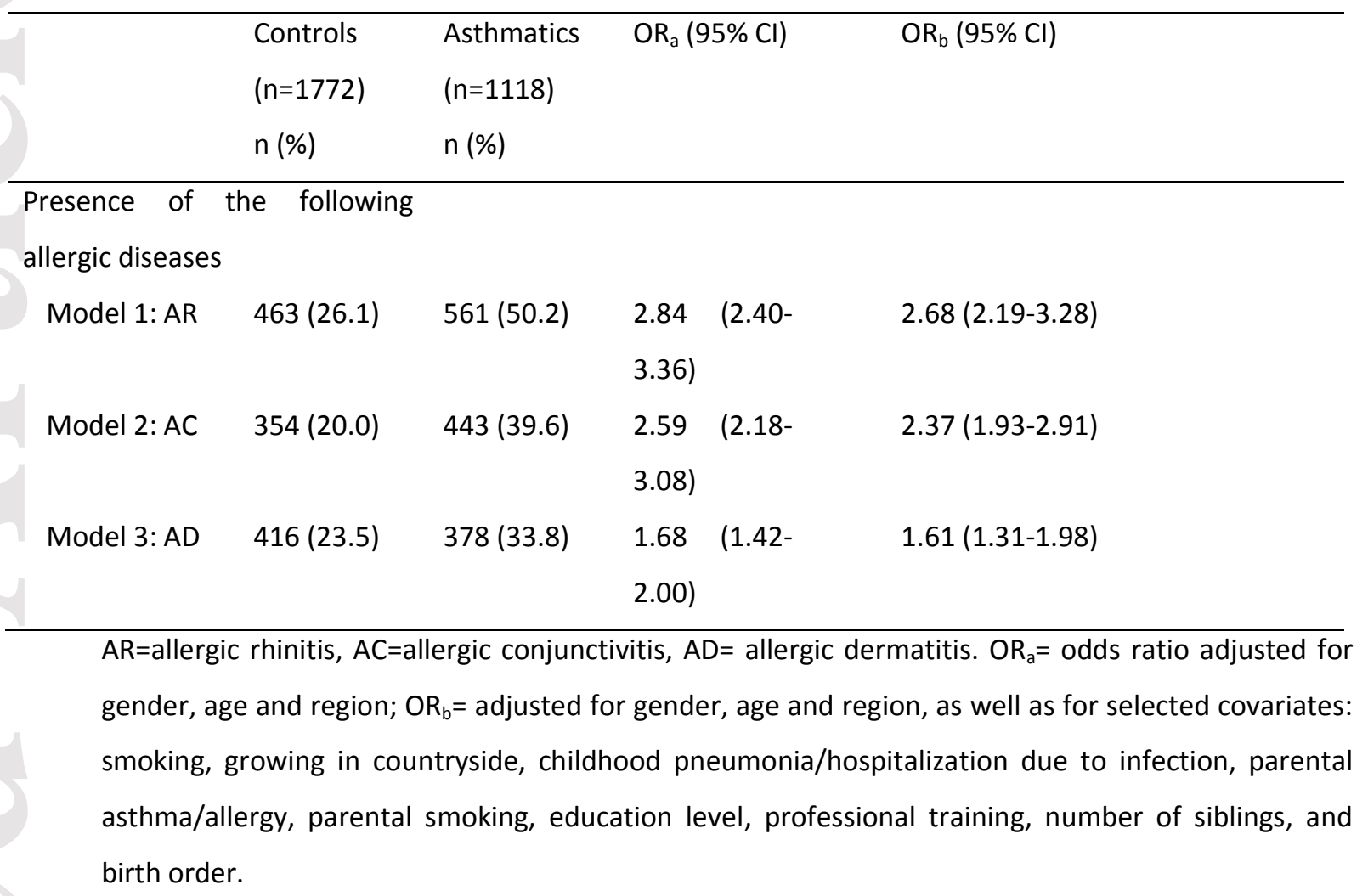

This article is protected by copyright. All rights reserved. 

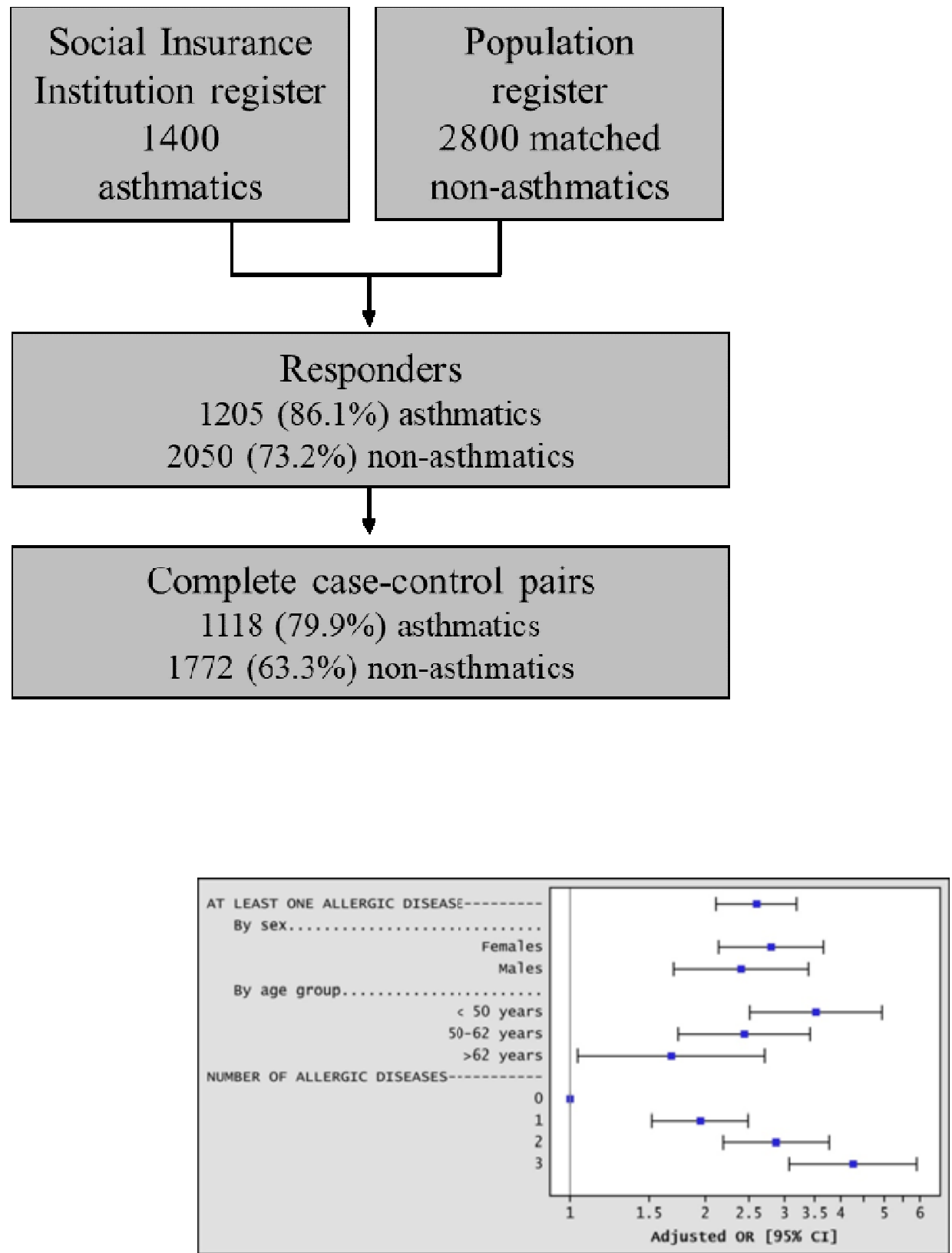